\title{
ANALISIS TANAH EKSPANSIF DENGAN PERBAIKAN SEMEN PUTIH DAN SEMEN HITAM MENGGUNAKAN UCT
}

\author{
Elendra $^{1}$ dan Aniek Prihatiningsih ${ }^{2}$ \\ ${ }^{1}$ Program Studi Sarjana Teknik Sipil, Universitas Tarumanagara, Jl. Letjen S. Parman No.1 Jakarta \\ Email: elendralukman27@gmail.com \\ ${ }^{2}$ Program Studi Sarjana Teknik Sipil, Universitas Tarumanagara, Jl. Letjen S. Parman No.1 Jakarta \\ Email:aniekp@ft.untar.ac.id
}

\begin{abstract}
ABSTRAK
Dalam bidang geoteknik tanah berperan penting dan merupakan langkah awal yang pen-ting dalam bidang konstruksi yang berkaitan erat dengan struktur sebuah bangunan. Tanah ekspansif adalah tanah yang kandungan lempungnya memiliki potensi kembang-susut akibat perubahan kadar air sehingga mengakibatkan perubahan volume tanah. Penelitian ini dilaksanakan untuk melihat pengaruh perbaikan tanah ekspansif yang dicampur semen hitam dan semen putih dengan kadar 3\%, 6\%, dan 9\% dalam waktu pemeraman 9 hari, 12 hari, dan 15 hari. Kesimpulan yang dapat ditarik dari pengujian ini adalah tanah ekspansif yang dicampur dengan semen putih memiliki daya dukung tanah dalam bentuk nilai kuat tekan bebas yang lebih besar dibandingkan dengan semen hitam. Nilai kuat tekan bebas tertinggi didapatkan dari pengujian dengan campuran semen putih $9 \%$ dengan waktu peram 15 hari yaitu $1004.02 \mathrm{kN} / \mathrm{m}^{2}$.

Kata kunci: Tanah Ekspansif, Semen Putih, Semen Hitam, Kuat Tekan Bebas, Daya Dukung Tanah.
\end{abstract}

\section{PENDAHULUAN}

\section{Latar Belakang}

Dalam bidang Teknik Sipil tanah sangat berkaitan erat dengan struktur sebuah bangunan. Selain sebagai titik awal dalam pembangunan, tanah berfungsi mendukung beban-beban bangunan di atasnya. Tanah ekspansif adalah tanah yang kandungan lempungnya memiliki potensi kembang-susut akibat perubahan kadar air sehingga mengakibatkan perubahan volume tanah. Jika kadar air dalam tanah ekspansif tinggi maka akan mengurangi kekuatan daya dukung tanah sehingga berakibat tekanan tanah aktif menjadi tinggi dan terjadi keruntuhan bangunan. Metode perbaikan tanah semakin maju dan selalu diaplikasikan dalam pekerjaan konstruksi. Tujuan dari perbaikan tanah untuk menaikkan daya dukung dan kuat geser tanah, juga untuk mengontrol stabilitas vo-lume tanah. Tujuan penelitian ini untuk memaksimalkan hasil dari pengaruh penambahan semen, khususnya untuk membandingkan penggunaan semen putih (White Portland Cement) dengan semen hitam (Portland Composite Cement) apabila dicampuran pada tanah ekspansif. Dari hasil percobaan ini dapat diketahui dan didapatkan nilai daya dukung tanah sebagai perbandingan nilai kekuatan antara tanah ekspansif yang dicampurkan semen putih dan semen hitam. Pencampuran semen putih dan semen hitam ini dilakukan dengan berbagai macam variasi perbandingan, yaitu sebanyak 3\%, 6\%dan 9\% dari berat kering sample tanah dengan waktu pemeraman 9 hari, 12 hari dan 15 hari.

Pengujian dilakukan di Laboratorium Mekanika Tanah Universitas Tarumanagara dan didapat hasil pengaruh penambahan antara penggunaan semen putih dan semen hitam yang dicampur dengan tanah ekspansif. Pengujian kuat tekan dilakukan dengan pengujian dengan alat Unconfined Compression Test.

\section{Batasan Masalah}

Batasan-batasan masalah dalam penelitian ini adalah:

1. Perbaikan tanah menggunakan semen putih dan semen hitam

2. Rasio pencampuran dari Semen Putih dan Semen Hitam masing-masing 3\%, 6\%, dan 9\%

3. Waktu pemeraman 9 hari, 12 hari dan 15 hari.

4. Tanah yang digunakan pada pengujian lolos saringan no.4

5. Pengujian dilakukan dengan Unconfined Compression Test.

6. Pembuatan sample dalam kondisi undisturbed. 


\section{Rumusan Masalah}

Rumusan masalah yang dibahas:

Pengecekkan karakteristik tanah ekspansif untuk sample benda uji dengan menghitung nilai uji kuat tekan bebas untuk campuran tanah dengan semen hitam dan semen putih masing-masing dengan durasi pemeraman 9 hari, 12 hari, dan 15 hari, serta dalam kadar rasio pencampuran semen yang bervariasi, dan analisis kenaikan nilai uji kuat tekan dari campuran semen hitam dengan semen putih

\section{Tujuan Penelitian}

Adapun tujuan yang ingin dicapai dalam penulisan skripsi ini:

1. Menganalisis hasil kuat tekan bebas pada tanah

2. perbandingan antara pencampuran Semen Putih dan Semen Hitam dengan metode pemeraman secara terpisah menggunakan uji alat UCT.

3. Mendapatkan hasil kuat tekan tanah ekspansif yang dicampur dengan Semen Putih dan Semen Hitam dengan rasio pencampuran dan waktu yang bervariasi.

\section{TINJAUAN PUSTAKA}

\subsection{Klasifikasi Karakteristik Tanah}

Keberhasilan sebuah pembangunan terletak pada dasar yang menopang sistem pembangunan terserbut, salah satu bagian terpenting dalam keberhasilan tersebut adalah tanah. Tanah merupakan lahan penting bagi aktivitas manusia di bumi termasuk bagi pertumbuhan tanaman. Tanah memiliki sifat bervariasi yang terdiri dari sifat fisik, kimia, dan biologi. Tanah terjadi sebagai produk pecahan dari batuan yang mengalami pelapukan mekanis atau kimiawi. Pelapukan mekanis terjadi apabila batuan berubah menjadi fragmen yang lebih kecil tanpa terjadinya suatu perubahan kimiawi dengan faktor-faktor yang mempengaruhi, yaitu pengaruh iklim, eksfoliasi, erosi oleh angin dan hujan, abrasi, serta kegiatan organik. Sedangkan pelapukan kimiawi meliputi perubahan mineral batuan menjadi senyawa mineral yang baru dengan proses yang terjadi antara lain seperti oksidasi, larutan (solution), pelarut (leaching).

\subsubsection{Klasifikasi Tanah Berdasarkan Unified Soil Classification System (USCS)}

Berdasarkan sistem USCS, tanah terbagi menjadi tanah berbutir kasar dan tanah berbutir halus. Tanah berbutir kasar terbagi menjadi kerikil, dengan notasi G (gravel) dan pasir dengan notasi S (sands). Keduanya terbagi ke dalam empat golongan, yaitu:

a. Gradasi baik dan cukup bersih, diartikan hanya sedikit kandungan material berbutir halus, dinotasikan W (well graded).

b. Gradasi buruk dan cukup bersih, dinotasikan P (poorly graded).

c. Gradasi baik dengan lempung sebagai pengikat, dinotasikan C (clay).

d. Gradasi kasar dan mengandung tanah berbutir halus, dinotasikan M (silt)

e. Tanah berbutir halus terbagi menjadi:

f. Tanah lanau anorganik (tidak mengandung material organik) dan tanah yang mengandung pasir yang berbutir sangat halus-dinotasikan M (silt)

g. Tanah lempung Anorganik dinotasikan C (clay).

h. Tanah lanau dan lempung organik dinotasikan O (organic).

i. Tanah dengan kadar organik sangat tinggi dinotasikan Pt (peat).

\subsubsection{Klasifikasi Tanah berdasarkan AASHTO}

Sistem ini dibuat olehAmerican Association of state Highway and Transportation Officials yang bertujuan untuk menganalisa material subgrade dalam pembangunan. Sistem AASHTO mengklasifikasikan tanah ke tujuh kelompok besar yaitu, A-1 sampai dengan A-7, dimana A-1 sampai A-3 adalah tanah kurang dari 35\% dari jumlah butiran tanah yang lolos ayakan saringan nomor 200. Sedangkan A-4 sampai dengan A-7 untuk kelompok butiran yang lebih dari 35\% dari jumlah butiran yang lolos ayakan saringan nomor 200.

Berikut hasil pengujian karakteristik tanah dan kesimpulan sesuai dengan klasifikasi tanah berdasarkan USCS dan AASHTO: 
Tabel 1. Hasil Pengujian Karakteristik Tanah

\begin{tabular}{lccc}
\hline & A & B & C \\
\hline Water Content & 41 & 41 & 41 \\
\hline 12 Hari & 2,67 & 2,65 & - \\
\hline
\end{tabular}

Tabel 2. Hasil Pengujian Atterberg Limits

\begin{tabular}{lcc}
\hline & $\boldsymbol{A}$ & $\boldsymbol{B}$ \\
\hline LL & 75,51 & 75,51 \\
\hline PL & 42,68 & 39,02 \\
\hline IP & 32,83 & 36,49 \\
\hline
\end{tabular}

Tabel 3. Hasil Pengujian dengan Semen Hitam

\begin{tabular}{lcc}
\hline & $\boldsymbol{A}$ & $\boldsymbol{B}$ \\
\hline Kerikil & 0 & 0 \\
\hline Pasir & 5,09 & 5,29 \\
\hline Lempung & 31,67 & 27,06 \\
\hline Lanau & 63,23 & 67.65 \\
\hline
\end{tabular}

\subsection{Karakteristik Tanah Ekspansif}

Tanah ekspansif adalah tanah yang akibat perubahan perubahan kadar air mengalami perubahan volume. Tanah ekspansif mengandung mineral-mineral seperti smektit, bentonit, montmorillonite, beidellite, vermikulit, atapulgit, nontronite, illite, klorit, dan beberapa garam sulfat sehingga mengakibatkan terjadi pengembangan. Tanah ekspansif akan mengembang ketika basah dan mengerut ketika kering. Selain itu, tanah eksansif juga memiliki tingkat kesuburan dari level sedang hingga tinggi, sehingga berbagai jenis tanaman dapat hidup di atasnya.

Dengan terjadinya perubahan volume, kekuatan struktur bangunan yang berdiri di atas tanah menjadi lemah karena mengakibatkan bangunan yang berdiri di atasnya menjadi terangkat saat kondisi kadar air tinggi. Sebaliknya, pengeringan berakibat pada penyusutan dan menghlangkan daya dukung bangunan yang berdiri di atasnya. Terjadinya celah atau retakkan memudahkan penetrasi air lewat tanah yang menciptakan tegangan berulang pada tanah.

\subsection{Stabilisasi Tanah dengan Semen Putih dan Semen Hitam.}

Stabilisasi tanah adalah metode yang digunakan untuk menjaga potensi pada lapisan tanah, meningkatkan daya dukung tanah, dan menurunkan permeabilitas tanah. Stabilisasi tanah dilakukan dengan menggunakan metode stabilisasi kimia. Pada umumnya stabilisasi kimia memperbaiki parameter tanah dengan membentuk senyawa baru dalam massa tanah.

Semen adalah bahan yang memiliki sifat merekatkan bahan-bahan padat menjadi satu kesatuan yang kuat. Dapat diartikan juga sebagai bahan yang memiliki sifat adhesive dan cohesive untuk mengikat batu kerikil dan pasir. Semen putih (White Portland Cement) adalah jenis semen mutu tinggi yang digunakan untuk keperluan pekerjaan arsitektur, precast, dan beton. Bahan utama semen putih adalah kalsit limestone murni. Semen hitam (Portland Composite Cement) adalah semen hidrolik yang dihasilkan oleh penghancuran klinker yang dasarnya terdiri dari kalsium silikat hidrolik (ASTM C 150). Semen jenis ini paling banyak digunakan dalam proses konstruksi beton.

\subsection{Uji Unconfined Compression Test (UCT)}

Dalam pengujian ini, sample bersifat undrained karena penekanan yang relatif cepat, sehingga tidak ada air yang keluar dari pori sample tanah selama pengujian (Hardiyatmo, 2002).

Pengujian ini bertujuan untuk menentukan kuat tekan bebas pada tanah kohesif dan memperoleh kuat geser tanah kohesif secara cepat dan ekonomis. Kuat tekan bebas adalah nilai yang diperoleh tegangan aksial maksimum yang dapat ditahan oleh benda uji sebelum terjadi keruntuahn geser.

Rumus untuk menghitung parameter uji kuat tekan bebas:

$$
\varepsilon=\Delta \mathrm{L} / \mathrm{L}_{0}
$$


Keterangan: $\varepsilon=$ Regangan aksial yang dinyatakan dalam persen, $\Delta \mathrm{L}=$ Deformasi aksial benda uji, $\mathrm{L}_{0}=\mathrm{Panjang}$ atau tinggi awal benda uji.

$$
\mathrm{A}=\mathrm{A}_{0} /{ }_{1-\varepsilon}
$$

Keterangan: $\mathrm{A}=$ Luas penampang setelah dikoreksi, $\mathrm{A}_{0}=$ Luas penampang awal benda uji.

$$
\mathrm{q}_{\mathrm{u}}=\mathrm{P} / \mathrm{A}
$$

Keterangan: $\mathrm{P}=$ beban (gaya tekan) $=\mathrm{n} \times \beta, \mathrm{n}=$ Pembacaan pada jarum load dial, $\mathrm{B}=$ Kalibrasi angka pada jarum proving ring.

\section{METODOLOGI PENELITIAN}

\subsection{Prosedur Penelitian Laboratorium}

Penelitian di laboratorium bertujuan untuk menganalisa data secara lebih rinci dan akurat tentang sifat dan jenis tanah dalam keadaan alami dan diberi pembebanan pada sample.

Jenis pengujian di laboratorium terbagimenjadi dua, yaitu:

A. Sifat fisik tanah (Index Properties) yaitu, sifat alami tanah dalam menentukan karakteristik tanah.

B. Sifat mekanis tanah (Engineering Properties) yaitu, sifat tanah setelah diberi pembebanan untuk menentukan parameter tanah.

1. Karakteristik Tanah

Uji karakteristik tanah meliputi uji kadar air (water content) yang terdiri dari batas atterberg yaitu, batas cair (LL), batas plastis (PL), batas susut (SL), serta penentuan specific gravity. Metode yang digunakan adalah pengeringan dengan oven, pengeringan dengan pembakaran memakai alcohol, dan pengujian dengan speedy.

2. Penyebaran Butiran (Grand Size Distribution)

Metode penyebaran butiran bertujuan untuk mengetahui butiran tanah yang berukuran lebih besar dari 0.075 milimeter. Untuk ukuran butiran yang kurang dari 0.075 milimeter digunakan analisa hydrometer.

3. Kuat Geser Tanah (Shear Strength of Soils)

Untuk mendapatkan nilai kekuatan geser tanah dapat dilakukan Unconfined Compression Test karena sample dibentuk sesuai ukuran tanpa merusak susunan partikel. Benda uji dimasukkan ke dalam tabung yang bagian dalamnya sudah diolesi oil sambil ditekan lalu dikeluarkan dan diletakkan di bawah mesin tekan yang selanjutnya dilakukan pembacaan pada load dial dan jarum proving ring. 


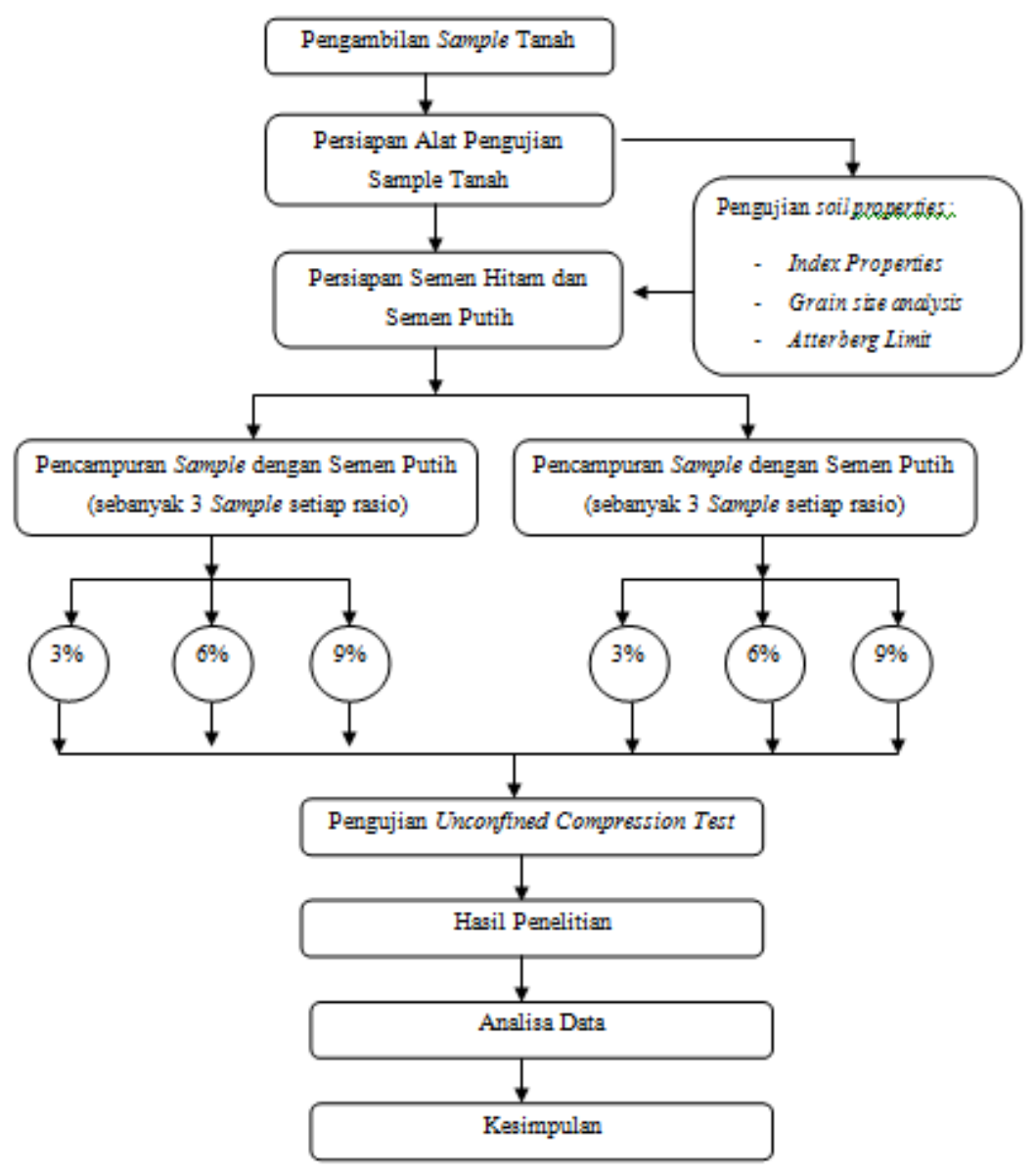

Gambar 1. Flowchart Pengujian Sample di Laboratorium

\subsection{Pembuatan Sample UCT}

Pembuatan sample dimulai dengan mengukur tinggi dan diameter silinder mold UCT agar mendapatkan volume dari silinder mold UCT, selanjutnya volume tersebut menjadi dasar untuk menghitung berat sample pada kondisi kepadatan maksimum. Untuk pemadatan sample dibagi 3 lapis agar setiap lapis diharapkan pada kondisi kepadatan yang sama, maka berat tanah kering pada kondisi kepadatan maksimum dibagi menjadi 3. Silinder mold sebelum digunakan harus dilapisi dengan pelumas agar memudahkan proses keluarnya sample tanah dari mold. Sample tanah dimasukkan ke silinder mold lalu ditumbuk sampai pada batas 1/3 tinggi silinder mold dan di ukur dengan bantuan penggaris. Kemudian di tambahkan sepertiga berat tanah kedua dan dipadatkan sampai pada batas 2/3 silinder mold dan terakhir sebelum ditambahkan tanah dipasang dahulu PVC case agar tanah tidak tumpah. Lalu ditumbuk sampai batas ketinggian silinder mold. Penumbukan tanah dibantu dengan palu karet agar pemadatan rata. 

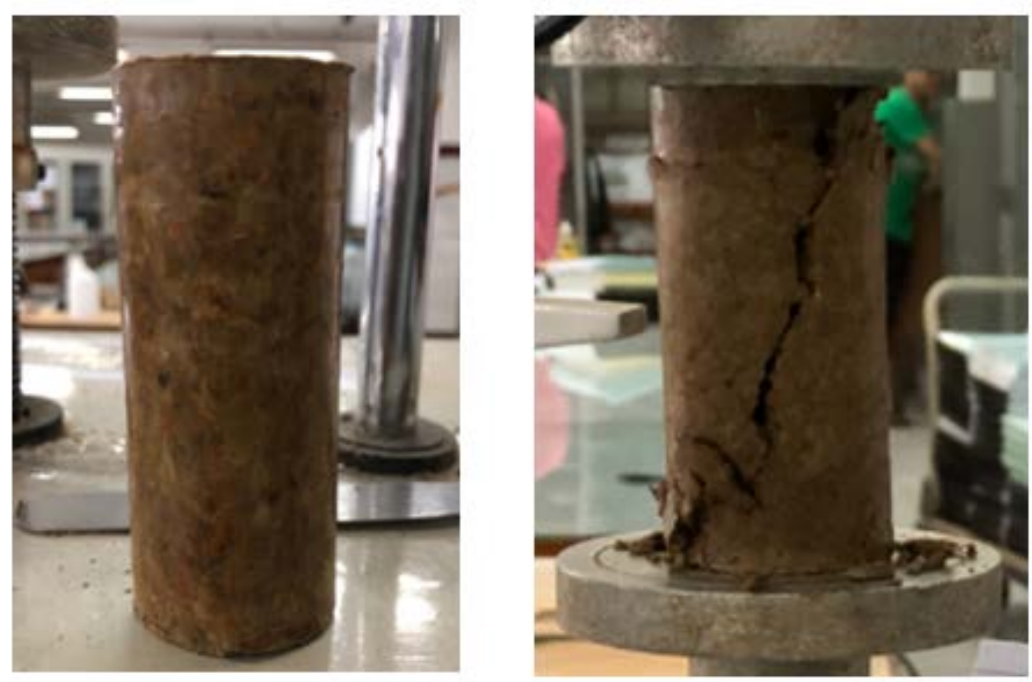

Gambar 1. Kondisi Sebelum dan Sesudah Pengujian Sample Tanah dengan UCT

\section{DATA PENELITIAN}

Tabel 4. Hasil Pengujian dengan Semen Hitam

\begin{tabular}{lccc}
\hline & $\mathbf{3 \%}$ & $\mathbf{6 \%}$ & $\mathbf{9 \%}$ \\
\hline 9 Hari & 363 & 425,95 & 619,48 \\
\hline 12 Hari & 459,53 & 541,15 & 815,92 \\
\hline 15 Hari & 634,83 & 696,12 & 920,86 \\
\hline
\end{tabular}

Tabel 5. Hasil Pengujian dengan Semen Putih

\begin{tabular}{lccc}
\hline & $\mathbf{3 \%}$ & $\mathbf{6 \%}$ & $\mathbf{9 \%}$ \\
\hline 9 Hari & 425,53 & 578.25 & 834,78 \\
\hline 12 Hari & 560,40 & 634,83 & 918,31 \\
\hline 15 Hari & 699,61 & 753,42 & 1004,02 \\
\hline
\end{tabular}

Tabel 3. Persentase Kenaikan Nilai Kuat Tekan Bebas dari Semen Hitam ke Semen Putih

\begin{tabular}{lccc}
\hline & $\mathbf{3 \%}$ & $\mathbf{6 \%}$ & $\mathbf{9 \%}$ \\
\hline 9 Hari & 14,69 & 26,34 & 25,79 \\
\hline 12 Hari & 18,00 & 14,76 & 11,15 \\
\hline 15 Hari & 16,28 & 7,61 & 8,28 \\
\hline
\end{tabular}

\section{ANALISIS DAN PEMBAHASAN}

Dari hasil pengujian, didapatkan hasil tanah ekspansif yang dicampur semen putih dengan kadar rasio 9\% memiliki nilai rata-rata kuat tekan bebas tertinggi sebesar $1004.02 \mathrm{kN} / \mathrm{m}^{2}$. Nilai kuat tekan bebas terkecil didapatkan dari hasil campuran tanah ekpansif dengan semen hitam menggunakan rasio $9 \%$ sebesar $363 \mathrm{kN} / \mathrm{m}^{2}$. Nilai kuat tekan bebas yang besar didapatkan dari hasil pengujian dengan waktu pemeraman yang lebih lama karena memberi waktu semen untuk merekat dengan tanah. Sebaliknya nilai kuat tekan bebas yang kecil merupakan hasil dari rentang waktu yang terlalu sedikit untuk semen merekat dengan tanah ekspansif. Dari hasil pengujian, persentase kenaikan nilai kuat tekan bebas didapatkan dalam waktu pemeraman 9 hari dengan kadar rasio pencampuran dengan semen hitam dan putih sebesar 6\% yaitu 26.34\%. Penggunaan semen putih menghasilkan nilai kuat tekan bebas yang lebih tinggi daripada semen hitam karena semen putih memiliki kandungan daya perekat yang lebih kuat dibandingkan 
semen hitam. Nilai kuat tekan bebas pencampuran semen putih tertinggi didapatkan sebesar $1004.02 \mathrm{kN} / \mathrm{m}^{2}$ dengan waktu pemeraman 15 hari dan nilai kuat tekan bebas pencampuran semen hitam tertinggi didapatkan sebesar 920.86 $\mathrm{kN} / \mathrm{m}^{2}$ dengan waktu pemeraman 15 hari.

\section{KESIMPULAN}

Dari hasil pengujian laboratorium, penulis menarik kesimpulan berdasarkan hasil uji karakterisik tanah di laboratorium Universitas Tarumanagara terhadap tanah di Jalan Science Timur 2 Jayamukti, Cikarang Pusat, Bekasi, Jawa Barat, dihasilkan nilai IP 36.49\% dan kandungan lempung atau clay $31.67 \%$ sehingga dapat dikategorikan tanah di daerah tersebut adalah tanah ekspansif. Dari hasil pengujian dengan waktu pemeraman selama 15 hari dan penambahan 9\% didapatkan nilai kuat tekan bebas sebesar $1004.02 \mathrm{kN} / \mathrm{m}^{2}$ pada sample tanah yang dicampur dengan semen putih dan nilai kuat tekan bebas sebesar $920.86 \mathrm{kN} / \mathrm{m}^{2}$ pada sample tanah yang dicampur dengan semen hitam. Nilai tegangan maksimum didapat pada kondisi pencampuran dengan semen putih. Penambahan semen putih menghasilkan nilai kuat tekan bebas yang lebih besar daripada penambahan menggunakan semen hitam. Durasi pemeraman yang dicampur pada sample tanah mempengaruhi hasil pengujian kuat tekan bebas dimana semakin lama durasi pemeraman menghasilkan nilai kuat tekan bebas yang besar karena semen dan tanah saling mengikat.

\section{DAFTAR PUSTAKA}

Ali, M. dan Satibi, S. (2015). Pengaruh Penambahan Semen terhadap Kuat Geser Lempung Sebelum dan Sesudah Penjenuhan. Jom FTeknik Volume 2 Nomor 1. Universitas Riau.

ASTM Standard D 2166-00. 2000. Standart Test Method for Unconfined Compressive Strength for Cohesive Soil. ASTM International, West Conshohocken, PA.

Das, Braja M. (1991). Mekanika Tanah (Prinsip-prinsip Rekayasa Geoteknis) Jilid I. Penerbit Erlangga. Jakarta. Das, Braja M. dan Sobhan, K. (2012). Principles of Geotechnical Engineering 8 th edition, SI. Amerika. Hardiyatmo, H. C. (2002). Mekanika Tanah I. Penerbit Gadjah Mada University Press. Yogyakarta. 
